\title{
The Conformation and Assignment of the Proton NMR Spectrum in Water of DX600, a Bioactive Peptide with a Random Coil Conformation
}

\author{
Wayne E. Steinmetz, Timothy N. Carrell, and Richard B. Peprah \\ Chemistry Department, Pomona College, Claremont, CA 91711, USA \\ Correspondence should be addressed to Wayne E. Steinmetz, wsteinmetz@pomona.edu
}

Received 7 November 2010; Revised 16 January 2011; Accepted 1 February 2011

Academic Editor: Stefan Schmatz

Copyright (c) 2011 Wayne E. Steinmetz et al. This is an open access article distributed under the Creative Commons Attribution License, which permits unrestricted use, distribution, and reproduction in any medium, provided the original work is properly cited.

DX600, a small peptide with 26 residues, is a potent, highly selective inhibitor of angiotensin converting enzyme 2 (ACE2). A range of NMR methods including TOCSY and ROESY yield an assignment of its proton spectrum in water and constraints on its conformation. Constrained molecular dynamics simulations of solvated DX600 show that the peptide's most abundant conformer adopts a predominantly random coil conformation. Constrained by the disulfide bond, its backbone defines an overhand knot with frayed ends.

\section{Introduction}

Angiotensin converting enzyme (ACE), a dipeptidase, is a key component of the renin-angiotensin system that regulates blood pressure $[1,2]$. It catalyzes the conversion of inactive angiotensin I to angiotensin II, a potent vasoconstrictor, and the hydrolysis of bradykinin, a vasodilator. Consequently the treatment of hypertension makes extensive use of potent, selective inhibitors of ACE such as captopril and trandolapril [3]. Given the medical importance of the inhibition of ACE, the drug-design community has produced several Xray structures of ACE-inhibitor complexes [4] and NMR solution-phase structures of the free inhibitors $[5,6]$.

ACE2 is a closely related enzyme which exhibits considerable sequence and structural homology with ACE $[7,8]$. Both are peptidases with zinc at the active center. However, there are differences. Whereas ACE is widely distributed in the body, ACE2 is found principally in the heart, kidney, and testis. It cleaves the terminal leucine residue from the decapeptide angiotensin I and does not play a major role in the control of blood pressure. Knockout studies with mice indicate that ACE2 affects cardiac function [9].

To date, no inhibitors of ACE2 have entered clinical practice [3]. However, inhibitors of ACE2 have been developed as tools for exploring and modulating its biological function $[10,11]$. Huang et al. screened peptide libraries displayed on phage and identified six highly potent inhibitors of ACE2 which do not inhibit ACE [12]. DX600, the most potent in the set with $K_{i}$ (the reciprocal of the equilibrium constant for the binding of the inhibitor, e.g., DX600, to the enzyme) equal to $2.8 \mathrm{nM}$, has the sequence $\mathrm{Gly}^{1}$ Asp $^{2}-$ Tyr $^{3}-$ Ser $^{4}-\mathrm{His}^{5}-\mathrm{Cys}^{6}-\mathrm{Ser}^{7}-\mathrm{Pro}^{8}-\mathrm{Leu}^{9}-\mathrm{Arg}^{10}-\mathrm{Tyr}^{11}-\mathrm{Tyr}^{12}$ Pro $^{13}$-Trp ${ }^{14}$ Trp $^{15}$-Lys $^{16}{ }^{16}$ Cys $^{17}-$ Thr $^{18}{ }^{1}$ Tyr $^{19}{ }^{19}$ Pro $^{20}-$ Asp $^{21}-$ Pro $^{22}$ $\mathrm{Glu}^{23}-\mathrm{Gly}^{24}-\mathrm{Gly}^{25}-\mathrm{Gly}^{26}$. It is acetylated at the amino terminus and amidated at the carboxyl terminus and a disulfide bond links the two cysteine residues, Cys $^{6}$ and Cys ${ }^{17}$. DX600's properties as an inhibitor mark it as a candidate for an NMR study and its unusual composition makes it particularly attractive. The small peptide contains one disulfide bond, six aromatic residues $\left(\mathrm{Tyr}^{3}, \mathrm{Tyr}^{11}, \mathrm{Tyr}^{12}, \operatorname{Tr}^{14}, \operatorname{Tr}^{15}, \mathrm{Tyr}^{19}\right)$, four prolines, and six residues with charged side chains $\left(\mathrm{Asp}^{2}, \mathrm{His}^{5}, \mathrm{Arg}^{10}, \mathrm{Lys}^{16}, \mathrm{Asp}^{21}, \mathrm{Glu}^{23}\right)$. This is the first study of the NMR spectroscopy and molecular modeling of DX600. No X-ray structure has been published.

The 1D proton spectra of DX600 in $\mathrm{D}_{2} \mathrm{O}$ and $\mathrm{H}_{2} \mathrm{O}$ (Figure 1) show that it is present as several conformers with one conformer predominating. We have employed a broad range of $1 \mathrm{D}$ and $2 \mathrm{D}$ methods [13] and a combination of 

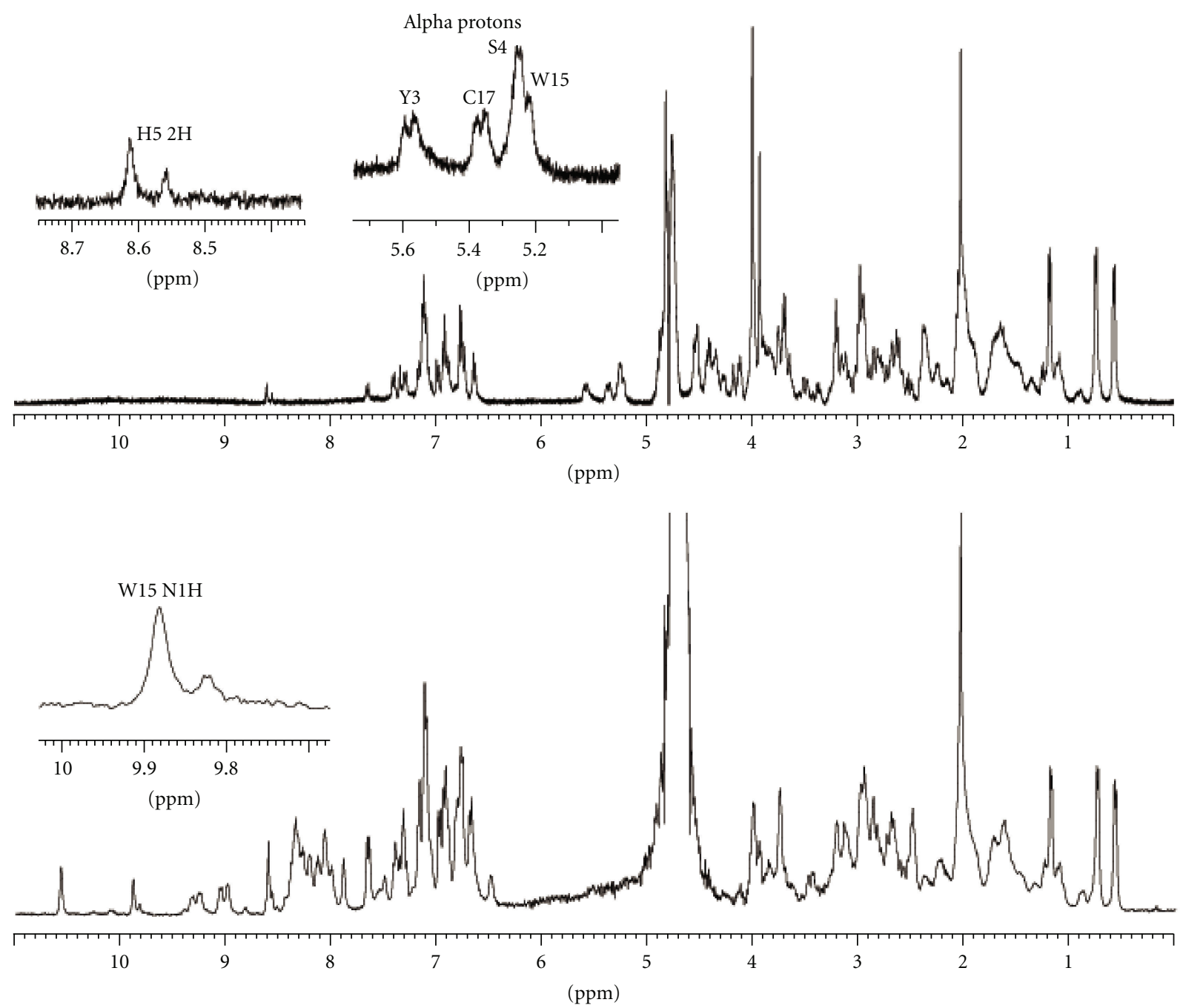

Figure 1: $400 \mathrm{MHz}^{1} \mathrm{H}$ spectrum of DX600 at $25^{\circ} \mathrm{C}$. (a): $0.65 \mathrm{mM}$ in $\mathrm{D}_{2} \mathrm{O}$, (b): $1.3 \mathrm{mM}$ in $90 \% \mathrm{H}_{2} \mathrm{O} / 10 \% \mathrm{D}_{2} \mathrm{O}$.

proton and carbon-13 spectra to assign the proton spectrum of the most abundant conformer of DX600 in water and to generate NMR constraints on its conformation. An analysis of the NMR results and constrained molecular dynamics (MD) simulations of solvated DX600 show the random-coil character of its most abundant conformer.

\section{Materials and Methods}

2.1. Sample Preparation. DX600 was purchased from Bachem Americas, Inc. and used without further purification. The supplier confirmed the sample's purity as $>96 \%$ via HPLC. 0.65 and $1.3 \mathrm{mM}$ solutions were prepared by dissolving samples of the peptide in $\mathrm{D}_{2} \mathrm{O}$ and $90 \% \mathrm{H}_{2} \mathrm{O} / 10 \% \mathrm{D}_{2} \mathrm{O}$ (volume \%). The 99.99 atom-\% $\mathrm{D}_{2} \mathrm{O}$ used to prepare the solutions was obtained from Aldrich. The $\mathrm{pH}$ of the resulting solutions at $25^{\circ} \mathrm{C}$ was 3.6 .

2.2. NMR Experiment. All NMR measurements were made on a Bruker DPX400 spectrometer equipped with an Avance console, a variable-temperature, proton/carbon, inverse detection probe, and hardware for pulse shaping and gradients. At its magnet field strength of 9.4 Tesla, the proton and carbon-13 Larmor frequencies are 400.13 and $100.62 \mathrm{MHz}$, respectively. Data acquisition and processing were performed with Version 3.0 of XWINNMR.

The water peak was used as an internal standard for the proton chemical shifts. The position of the water peak with respect to TSP was determined in a separate experiment with an aqueous solution of TSP. This approach of external referencing was validated at the end of the study. TSP was added to the sample and the chemical shifts measured directly with respect to TSP equaled the values obtained by the external referencing. Following the IUPAC recommendation, carbon13 referencing was based on the carbon-13 and proton $\Xi$ values and the position of the TSP singlet in the proton spectrum [14].

Solvent suppression was applied in the acquisition of all proton spectra. In the case of the $100 \% \mathrm{D}_{2} \mathrm{O}$ solutions, an inversion-recovery technique was effective in suppressing the HDO signal without saturating nearby peaks. 
TABLE 1: NMR acquisition and processing parameters.

\begin{tabular}{lcccccccccc}
\hline \multicolumn{1}{c}{ Method } & \multicolumn{4}{c}{ Detection period } & \multicolumn{5}{c}{ Evolution period } \\
& NS & $\mathrm{d} 1(\mathrm{~s})$ & TD & SI & SW $(\mathrm{ppm})$ & apod. & TD & SI & SW (ppm) & apod. \\
\hline 1D ${ }^{1} \mathrm{H}$ & 640 & 1 & $8 \mathrm{k}$ & $16 \mathrm{k}$ & 14.0 & & & & & \\
NOE diff. & $14 \mathrm{k}$ & 2 & $2 \mathrm{k}$ & $8 \mathrm{k}$ & 14.0 & em & & & & trap \\
COSY & 128 & 1 & $2 \mathrm{k}$ & $2 \mathrm{k}$ & 10.0 & trap & 128 & $1 \mathrm{k}$ & 10.0 & qsine \\
TOCSY & 88 & 2 & $2 \mathrm{k}$ & $2 \mathrm{k}$ & 10.9 & qsine & 256 & $1 \mathrm{k}$ & 14.0 & sine \\
2D J res. & 54 & 1.5 & $1 \mathrm{k}$ & $1 \mathrm{k}$ & 11.0 & sine & 256 & 256 & 0.12 & qsine \\
ROESY & 512 & 1 & $2 \mathrm{k}$ & $2 \mathrm{k}$ & 12.4 & qsine & 256 & $1 \mathrm{k}$ & 12.4 & qsine \\
HMQC & 800 & 2 & $1 \mathrm{k}$ & $2 \mathrm{k}$ & 10.0 & qsine & 128 & $1 \mathrm{k}$ & 221.8 & qsine \\
HMBC & 1128 & 2 & $1 \mathrm{k}$ & $1 \mathrm{k}$ & 11.0 & em & 128 & $1 \mathrm{k}$ & 221.8 & \\
\hline
\end{tabular}

apod.: apodization or windowing functions; em: exponential multiplication with $\mathrm{LB}=4 \mathrm{~Hz}$; qsine: squared cosine bell; trap: trapezoidal function.

The preparation period consists of a composite $180^{\circ}$ pulse, that is, $90_{y}^{\circ}-180_{x}^{\circ}-90^{\circ}$, followed by a delay, and finally a detection $90^{\circ}$ pulse. The delay is set at the null of the HDO peak following the inverting $180^{\circ}$ pulse. The delay, $2.0 \mathrm{~s}$ at $25^{\circ} \mathrm{C}$, is long compared with $T_{1}$ of the DX600 so its magnetization fully recovers when HDO is at its null. Because of radiation damping, this approach does not work for the $90 \% \mathrm{H}_{2} \mathrm{O}$ solutions. In this case, a standard Watergate pulse sequence is used as the preparation pulse [15].

Standard methods were used for the acquisition of the 1D spectra and the 2D COSY, TOCSY, 2D J resolved, HMQC, and HMBC spectra [15]. Temperature coefficients of chemical shifts were obtained from TOCSY spectra measured at $25^{\circ} \mathrm{C}$ and $45^{\circ} \mathrm{C}$ and $1 \mathrm{D}$ proton measurements at 2,25 , and $40^{\circ} \mathrm{C}$. The $\mathrm{d} 2$ delay for the HMQC and HMBC methods was $3.57 \mathrm{~ms}$, corresponding to ${ }^{1} J_{\mathrm{HC}}$ of $140 \mathrm{~Hz}$. The d6 HMBC delay was $60 \mathrm{~ms}$, corresponding to ${ }^{2,3} J_{\mathrm{HC}}$ of $8.3 \mathrm{~Hz}$. The acquisition and processing parameters are tabulated in Table 1. The pulse sequence of Hwang and Shaka was used to acquire the ROESY spectra [16]. The ROESY mixing times were 250 and $500 \mathrm{~ms}$. In order to increase the signal-to-noise ratio of weak nOe's involving well-resolved signals, we used the NOE difference method of Gordon and Wüthrich to perform a series of 1D experiments [17]. The standard method was modified to include Watergate solvent suppression. The experiment consists of a selective $180^{\circ}$ pulse (a Gaussian shaped pulse of length $38 \mathrm{~ms}$ ), a delay of $250 \mathrm{~ms}$ for the buildup of transfer of magnetization, and a Watergate detection pulse. The experiment is repeated with the application of the $180^{\circ}$ pulse set well off resonance, for example, $-8 \mathrm{ppm}$. The nOe's appear in the difference of the two spectra. The method of Stejskal and Tanner modified by $\mathrm{Wu}$ et al. involving bipolar gradient pulses and the LED pulse sequence (BP-LDE) was used to determine the translational diffusion constant $D_{T}$ [18]. Longsworth accurately determined $D_{T}$ of $\mathrm{HDO}$ in $\mathrm{D}_{2} \mathrm{O}$ [19]. The gradient coil was calibrated by running the method and observing the $\mathrm{HDO}$ signal in 99.99 atom $\% \mathrm{D}_{2} \mathrm{O}$. The following parameters were used in the diffusion measurements: TD, $8 \mathrm{k} ; \mathrm{d} 1,2 \mathrm{~s} ; \Delta$, $0.4 \mathrm{~s} ; \delta$ (gradient period), $2 \mathrm{~ms} ; T_{\mathrm{e}}, 5 \mathrm{~ms} ; \tau, 0.1 \mathrm{~ms}$; gradient current, between $1 \%$ and $99 \%$.

Upper bounds on distances between protons were extracted from the $500 \mathrm{~ms}$ ROESY spectrum using the methods used in our work on erythromycin [20, 21]. Values of ${ }^{3} J_{\mathrm{NH}, \alpha \mathrm{H}} \geq 9 \mathrm{~Hz}$ were converted into lower and upper bounds on $d_{\mathrm{NH}, \alpha \mathrm{H}}$, the distance between the amide and alpha protons $[21,22]$. The difference between the lower and upper bounds, $2.951 \AA$ and $3.002 \AA$, is proportionate to the uncertainty in the coupling constants and corresponds to an uncertainty of $30^{\circ}$ in the torsional angle.

2.3. Molecular Modeling. All modeling calculations were run on a Dell Precision 370 PC running under Red Hat Enterprise Linux Version 5 and using Versions 7.3 and 8.1 of SYBYL (Tripos, Inc., 1669 S. Hanley Road, St. Louis, MO). Molecular surfaces were calculated using MOLCAD. Random search parameters were set to the default values with the following exceptions: Bump Factors, 0.02; Ring Bond Closure, $10 \AA$; energy cutoff, $10 \mathrm{kcal} / \mathrm{mole}$. The force field for all calculations was MMFF94s, Halgren's modification of the Merck Molecular Force Field for peptides [23]. The integration time for all MD simulations was $1 \mathrm{fs}$. With the exception of the temperature and the length of the simulation, SYBYL default parameters were used for all MD simulations and energy minimizations. SYBYL provides a range of algorithms for energy minimization. Our energy minimization calculations employed the Powell algorithm with a Simplex initial optimization. Other available algorithms such as conjugate gradient and steepest descent were examined, but they were not used in the final calculations as they were less efficient. The MD simulations employed a canonical ensemble, for example, at constant volume.

The structure of DX600 was drawn with the Biopolymers module of SYBYL, thus guaranteeing the correct atom types and charges for the side chains: negative for Asp and Glu, positive for His, Lys, and Arg. These charge assignments did not change during the MD simulations. After formation of the disulfide bond, the torsional and distance constraints were added as quadratic penalty functions. The constraints were applied in all the simulations. In the MD simulations, a molecule of DX600 was embedded in a rectangular box containing 1651 water molecules and the energy of the system of water and solute molecules was minimized. In the simulations the interactions between the solute and the water molecules were defined by the MMFF94s force field. Periodic boundary conditions were employed in all MD 
and energy minimization calculations of hydrated DX600. The global-minimum structure generated by the in vacuo conformational search was a seed in 30 cycles consisting of the following steps: heating at $800 \mathrm{~K}$ for $10000 \mathrm{fs}$, cooling at $298 \mathrm{~K}$ for $1500 \mathrm{fs}$, and 200 cycles of energy minimization. Energy minimization of the structures generated by the final 11 cycles was then performed to convergence, that is, until the average gradient reached $0.05 \mathrm{kcal} / \mathrm{mol}-\AA \AA$. This final stage of optimization involved 6000 to 24000 additional cycles. The structures examined in Section 3.3 are based on the results of the final 11 cycles. Several pieces of evidence indicate equilibration of the structure. SYBYL's energy minimization module colors the atoms to indicate where forces act to change the structure. During the final stages of energy minimization, the color of the water molecules indicated the absence of gradients on the solvent molecules. Two distances, the separation of the alpha carbons on $\mathrm{Ser}^{4}$ and $\mathrm{Glu}^{23}$ and the distance between the center of the aromatic ring on $\mathrm{Tyr}^{3}$ and the amide nitrogen on $\mathrm{Asp}^{2}$, did not vary by more than $0.1 \AA$ during the final energy minimization. SYBYL's Monitor Distance module ruled out bad contacts between the peptide and the water. It displays violations where the distance between a pair of nonbonded atoms is less than the sum of the van der Waals radii; no violations were found in the final structures.

The in vacuo conformational search involved thousands of cycles of the SYBYL Random Search algorithm. In each cycle, randomly chosen torsional angles are changed and the resulting structure was minimized. This strategy which generated the global minimum and a small family of structures close in energy to the global minimum was very successful in conformational searches of derivatives of erythromycin. A detailed discussion of the methodology can be found in our papers on the NMR structures of these drugs $[21,22]$.

\section{Results and Discussion}

3.1. Analysis of the Survey Spectra. The proton survey spectra of DX600 dissolved in $\mathrm{D}_{2} \mathrm{O}$ and $\mathrm{H}_{2} \mathrm{O}$ (Figure 1) indicate a predominantly random-coil conformation for the most abundant conformer. The alpha protons of most residues are found within $0.3 \mathrm{ppm}$ of their random coil value. The small peptide has seven aromatic residues and ring current effects are expected to make extensive contributions to the chemical shifts. For example, the chemical shifts of three of the four downfield shifted alpha protons and the upfield shifted methyl protons of $\mathrm{Leu}^{9}$ are affected by nearby aromatic residues. Exchange experiments show the absence of extensive secondary structure. Serial measurements of the proton spectrum made immediately after dissolving the compound in $\mathrm{D}_{2} \mathrm{O}$ yielded no amide protons with one sample. Measurements with a second sample showed peaks for four amide protons that disappeared with a half life of ca. 15 minutes. They were later assigned to $\operatorname{Tr} p^{14}$, Lys $^{16}, \mathrm{Tyr}^{19}$, and $\mathrm{Asp}^{21}$. The temperature coefficients for the chemical shifts of these four amide protons, $d \delta / d T$, are $-3.0,-8.2,-0.6$, and $-5.5 \mathrm{ppb} /{ }^{\circ} \mathrm{C}$, respectively. The combination of measurable exchange kinetics and a small $d \delta / d T$, which is diagnostic for hydrogen bonding [24], indicates that the amide protons of $\operatorname{Trp}^{14}$ and $\mathrm{Tyr}^{19}$ form weak hydrogen bonds. However, one can conclude from the rapid exchange with $\mathrm{D}_{2} \mathrm{O}$ that most amide protons are exposed to the solvent and/or unprotected by strong hydrogen bonds. DX600 differs from mast cell degranulating peptide (MCD), another small peptide. Eight amide protons in $\mathrm{MCD}$, a peptide with 22 residues including one proline and two disulfide bridges, exchange slowly enough that they can be observed $30 \mathrm{~min}$. after dissolving the peptide [25]. In this case, the amide protons are stabilized by incorporation in an alpha-helix. The rapid exchange in DX600 indicates the absence of elements of secondary structure such as alphahelix and beta-sheet.

The survey spectra clearly show the presence of conformers of the most abundant species. Pairs of peaks in the ratio of 2-3:1 are seen at 9.9, 8.6, and $1.2 \mathrm{ppm}$. These are assigned, respectively, to the $\mathrm{N} 1 \mathrm{H}$ proton of $\operatorname{Trp}^{15}$, the $2 \mathrm{H}$ proton of $\mathrm{His}^{5}$, and the methyl protons of Leu ${ }^{9}$. The TOCSY spectrum also provides additional evidence for conformers. Furthermore minor $d_{\alpha \mathrm{N}}$ cross peaks assigned to $\mathrm{Glu}^{23} / \mathrm{Gly}^{24}$ connectivities appear in the ROESY spectrum. The $2 \mathrm{D}$ cross peaks assigned to conformers other than the most abundant species correlate positions in the $1 \mathrm{D}$ spectrum with peaks integrating to a mole fraction less than 0.3 . $1 \mathrm{D}$ spectra at temperatures up to $60^{\circ} \mathrm{C}$ and the ROESY spectrum at $45^{\circ} \mathrm{C}$ show no evidence of exchange broadening and cross peaks due to conformational exchange. The presence of conformers and their slow exchange can be attributed to the prolines and the disulfide bridge in DX600 and very likely involves cis- and trans-proline peptide bonds. The presence of cis- and transproline is a prominent feature of the NMR spectra of MCD [25].

The peaks in the proton spectrum of DX600 are much broader than one would expect for a peptide of its size. Qualitatively the spectrum of MCD is much better resolved. We attribute the result to the random coil conformation. DX600's overall shape, which is extended and asymmetric rather than spherical, leads to a decrease in the rotational diffusion constant $D_{R}$ and a corresponding decrease in $T_{2}$. Application of the BP-LDE method at $25^{\circ} \mathrm{C}$ yielded a translational diffusion constant $D_{T}$ of $(1.52 \pm 0.086) \times$ $10^{-10} \mathrm{~m}^{2} / \mathrm{s}$ in $\mathrm{D}_{2} \mathrm{O}$. A value for the spurious near spherical structure generated by the initial in vacuo modeling can be estimated using the well known relation from hydrodynamic theory between $D_{T}$ and the molecular radius $r: D_{T}=$ $k_{B} T / 6 \pi \eta r T$ where $\eta$ is the viscosity of solvent [26]. Using the molecular volume of the spherical form of DX600, one calculates $D_{T}=3.4 \times 10^{-10} \mathrm{~m}^{2} / \mathrm{s}$, a value greater than the observed value by a factor of roughly 2 .

The nonspherical, random coil conformation of DX600 and the resulting decreased values of $D_{R}$ and $D_{T}$ have several consequences for the measurement of NMR spectra. The ROESY spectrum is sparse and the cross-peaks are weak (Figure 2). The ROESY spectrum yields no long-range constraints and only four medium range constraints. Furthermore, the HMBC spectrum, in comparison with the HMQC spectrum, is sparse. A crucial component of the HMBC 
TABLE 2: Connectivities establishing the sequential assignment of DX600.

\begin{tabular}{lllllllllllllllllllllllllllll}
\hline $\mathrm{AA}$ & $\mathrm{G}$ & $\mathrm{D}$ & $\mathrm{Y}$ & $\mathrm{S}$ & $\mathrm{H}$ & $\mathrm{C}$ & $\mathrm{S}$ & $\mathrm{P}$ & $\mathrm{L}$ & $\mathrm{R}$ & $\mathrm{Y}$ & $\mathrm{Y}$ & $\mathrm{P}$ & $\mathrm{W}$ & $\mathrm{W}$ & $\mathrm{K}$ & $\mathrm{C}$ & $\mathrm{T}$ & $\mathrm{Y}$ & $\mathrm{P}$ & $\mathrm{D}$ & $\mathrm{P}$ & $\mathrm{E}$ & $\mathrm{G}$ & $\mathrm{G}$ & $\mathrm{G}$ \\
\hline$d_{\alpha \mathrm{N}}$ & $\mathrm{X}$ & $\mathrm{X}$ & $\mathrm{X}$ & & & & & $\mathrm{X}$ & & $\mathrm{X}$ & $\mathrm{X}$ & & & & $\mathrm{X}$ & $\mathrm{X}$ & $\mathrm{X}$ & & & & & & $\mathrm{X}$ & $\mathrm{X}$ & \\
$d_{\mathrm{NN}}$ & & & $\mathrm{X}$ & $\mathrm{X}$ & & $\mathrm{X}$ & & & & & & & & $\mathrm{X}$ & & & $\mathrm{X}$ & $\mathrm{X}$ & & & & & & \\
$d_{\beta \mathrm{N}}$ & & & & $\mathrm{X}$ & $\mathrm{X}$ & & & & & & & & & & & $\mathrm{X}$ & & & & $\mathrm{X}$ & & & & & \\
$d_{\alpha \alpha}$ & & & & & & & & & & & & & & & & & & & & & & & & & & & & \\
$d_{\alpha \beta}$ & & & & $\mathrm{X}$ & & & & & & & & & & & & & & & & & $\mathrm{X}$ & & & \\
\hline
\end{tabular}

Observed rOe/nOe connectivities following the nomenclature of Wüthrich [13]: $d_{\alpha \mathrm{N}}=d\left(\alpha \mathrm{H}_{i}, \mathrm{NH}_{i+1}\right), d_{\mathrm{NN}}=d\left(\mathrm{NH}_{i}, \mathrm{NH}_{i+1}\right), d_{\beta \mathrm{N}}=d\left(\beta \mathrm{H}_{i}, \mathrm{NH}_{i+1}\right), d_{\alpha \alpha}=$ $d\left(\alpha \mathrm{H}_{i}, \alpha \mathrm{H}_{i+1}\right), d_{\alpha \beta}=d\left(\alpha \mathrm{H}_{i}, \beta \mathrm{H}_{i, i+1}\right)$.

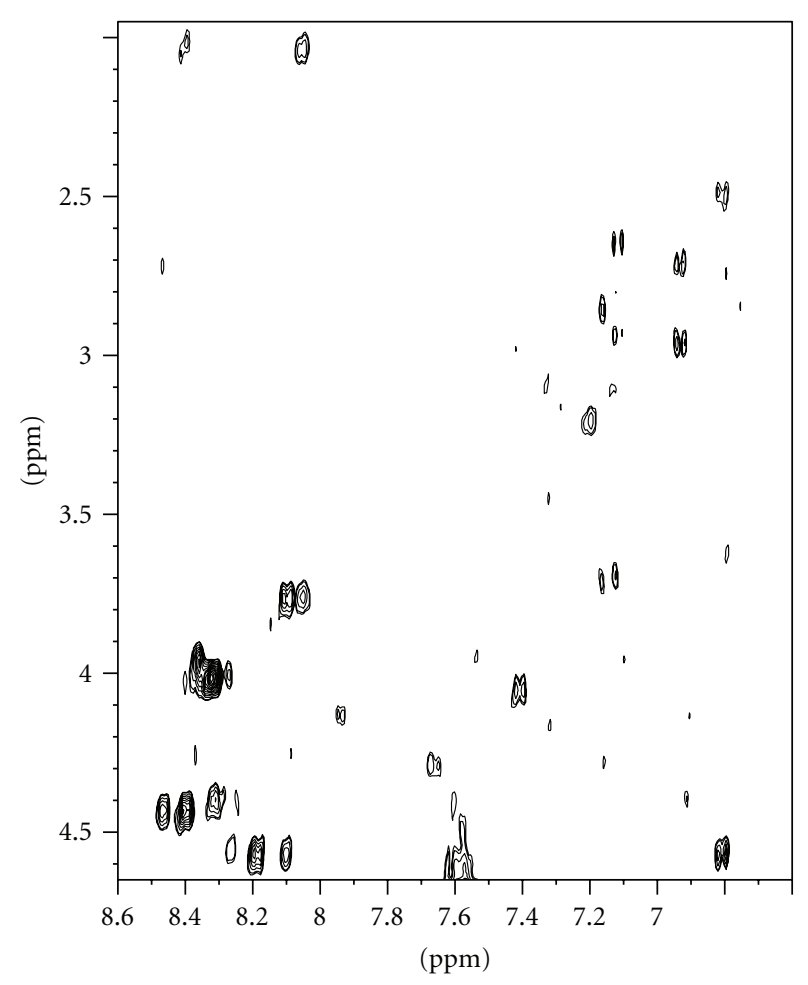

Figure 2: $500 \mathrm{~ms}$ ROESY spectrum at $25.0^{\circ} \mathrm{C}$ of $0.65 \mathrm{mM}$ DX600 in $90 \% \mathrm{H}_{2} \mathrm{O} / 10 \% \mathrm{D}_{2} \mathrm{O}$. Negative contours are shown.

method is a filter tuned to geminal and vicinal proton-carbon coupling. Small coupling constants require a long filter time, for example, $60 \mathrm{~ms}$, during which the magnetization decays to nearly zero. As a result the HMBC spectrum is dominated by spins attached to relatively mobile residues or side chains; these spins have a longer effective $T_{2}$ and their magnetization survives the filter. A short $T_{2}$ is a problem as it frustrates the use of HMBC in the assignment of the proton spectrum. However, the HMBC spectrum identifies the mobile regions of the molecule.

3.2. Assignment of the Proton Spectrum of the Most Abundant Conformer. The sequence-specific assignment of the aqueous solution of DX600 rests on a collection of techniques conducted at $25^{\circ} \mathrm{C}$. The assignment was validated by additional measurements at $45^{\circ} \mathrm{C}$. Anchor points for the assignment are the readily assigned spin systems: the acetyl

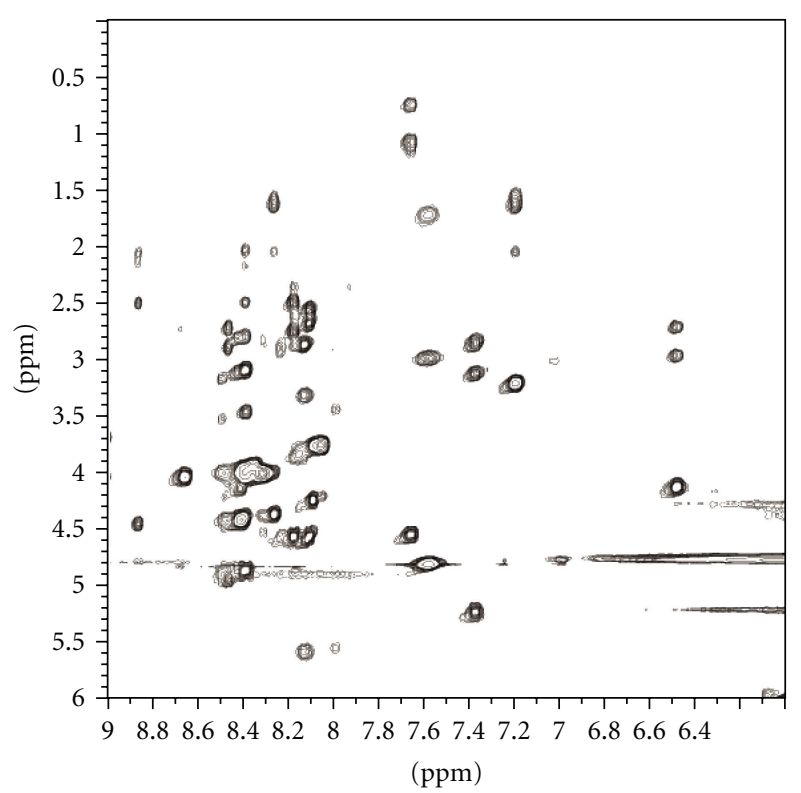

FIgure 3: TOCSY spectrum of $1.3 \mathrm{mM}$ DX600 in $90 \% \mathrm{H}_{2} \mathrm{O} / 10 \%$ $\mathrm{D}_{2} \mathrm{O}$ at $25^{\circ} \mathrm{C}$.

group at the amino terminus and the single copies of threonine, leucine, arginine, glutamic acid, and lysine. These amino acids have unique spin systems that can be completely sorted out in the TOCSY spectrum. An additional tag for the lysine spin system is the positively charged terminal ammonium group which yields a prominent, positive cross peak in the ROESY spectrum due to chemical exchange. The spin systems of the 26 residues, identified by the TOCSY spectrum in $\mathrm{H}_{2} \mathrm{O}$ (Figure 3 ) and the COSY spectrum in $\mathrm{D}_{2} \mathrm{O}$, are linked together by the ROESY spectrum (Figure 2). Weak nOe's were obtained by the NOE difference experiment. The assignment was further supported by rOe's between the beta and ring protons of the aromatic residues and HMBC crosspeaks for the mobile side chains of $\mathrm{Leu}^{9}, \mathrm{Thr}^{18}, \mathrm{Glu}^{23}$, and the aromatic residues. The evidence supporting the assignment is summarized in Table 2. Redundancy of the evidence is important given the sparseness of the ROESY spectrum, the weakness of many cross-peaks, the absence of several $d_{\alpha \mathrm{N}}$ cross-peaks, and the existence of conformers. The proton assignments for the most abundant conformer are given in Table 3. The assignment of the residues $\mathrm{Tyr}^{19}$ through $\mathrm{Glu}^{23}$ required special care because of the absence of ROESY 
TABLE 3: ${ }^{1} \mathrm{H}$ Assignments in ppm of $0.65-1.3 \mathrm{mM}$ DX600 in water at $25^{\circ} \mathrm{C}$.

\begin{tabular}{|c|c|c|c|c|c|c|c|c|}
\hline Res. & $\mathrm{NH}$ & $\alpha \mathrm{H}$ & $\beta \mathrm{H}$ & $\gamma \mathrm{H}$ & $\delta \mathrm{H}$ & other & ${ }^{3} J_{\mathrm{NH}, \alpha \mathrm{H}}(\mathrm{Hz})$ & ${ }^{3} J_{\alpha \mathrm{H}, \beta \mathrm{H}}(\mathrm{Hz})$ \\
\hline Ac & & & & & & methyl, 2.02 & & \\
\hline Gly $^{1}$ & 8.07 & 3.76 & & & & & 5 & \\
\hline Asp $^{2}$ & 8.11 & 4.55 & $2.67,2.57$ & & & & 8 & ca. 9 \\
\hline \multirow[t]{2}{*}{$\mathrm{Tyr}^{3}$} & 8.12 & 5.58 & $3.33,2.87$ & & & $2,6 \mathrm{H}, 7.11$ & 8 & 12 \\
\hline & & & & & & $3,5 \mathrm{H}, 6.77$ & & \\
\hline $\operatorname{Ser}^{4}$ & 9.10 & 5.23 & $4.02,3.88$ & & & & 8 & 7 \\
\hline $\mathrm{His}^{5}$ & 8.39 & 4.90 & $3.51,3.10$ & & & $2 \mathrm{H}, 8.61 ; 4 \mathrm{H}, 7.34$ & ca. 7 & ca. 11 \\
\hline $\mathrm{Cys}^{6}$ & 8.40 & 4.88 & $3.10,2.80$ & & & & ca. 7 & ca. 9 \\
\hline $\operatorname{Ser}^{7}$ & 8.09 & 4.21 & 3.75 & & & & 6 & \\
\hline Pro $^{8}$ & & 4.28 & $1.72,1.61$ & 2.02 & $3.98,3.87$ & & & \\
\hline Leu $^{9}$ & 7.65 & 4.52 & 1.08 & 1.18 & $0.75,0.57$ & & 8 & \\
\hline $\operatorname{Arg}^{10}$ & 8.27 & 4.40 & 2.10 & 1.62 & 3.20 & $\varepsilon \mathrm{NH}, 7.20$ & $<5$ & \\
\hline \multirow[t]{2}{*}{ Tyr $^{11}$} & 8.47 & 4.93 & $2.90,2.73$ & & & $2,6 \mathrm{H}, 6.93$ & 9 & \\
\hline & & & & & & $3,5 \mathrm{H}, 6.77$ & & \\
\hline \multirow[t]{2}{*}{$\operatorname{Tyr}^{12}$} & 8.19 & 4.60 & $2.76,2.50$ & & & $2,6 \mathrm{H}, 6.75$ & 7 & \\
\hline & & & & & & $3,5 \mathrm{H}, 6.64$ & & \\
\hline $\operatorname{Pro}^{13}$ & & 4.37 & 1.63 & 1.98 & 3.81 & & & \\
\hline \multirow[t]{3}{*}{$\operatorname{Trp}^{14}$} & 9.02 & 4.05 & $3.71,3.00$ & & & $2 \mathrm{H}, 7.12 ; 4 \mathrm{H}, 7.40$ & & \\
\hline & & & & & & $5 \mathrm{H}, 6.90 ; 6 \mathrm{H}, 7.31$ & & \\
\hline & & & & & & 7H, 7.65; N1H, 10.63 & & \\
\hline \multirow[t]{3}{*}{$\operatorname{Trp}^{15}$} & 7.38 & 5.22 & $3.15,2.88$ & & & $2 \mathrm{H}, 7.18 ; 4 \mathrm{H}, 7.17$ & $<4$ & 11 \\
\hline & & & & & & $5 \mathrm{H}, 6.88 ; 6 \mathrm{H}, 7.09$ & & \\
\hline & & & & & & 7H, 7.31; N1H, 9.90 & & \\
\hline \multirow[t]{2}{*}{ Lys $^{16}$} & 9.38 & 4.73 & 2.97 & 1.68 & $1.72,1.32$ & $\varepsilon \mathrm{H}, 3.02$ & 7 & \\
\hline & & & & 1.45 & & $\mathrm{NH}_{3}^{+}, 7.58$ & & \\
\hline Cys $^{17}$ & 9.32 & 5.38 & $2.99,2.80$ & & & & 9 & 10 \\
\hline $\operatorname{Thr}^{18}$ & 8.42 & 4.41 & 4.13 & 1.18 & & & 9 & $<2$ \\
\hline \multirow[t]{2}{*}{$\operatorname{Tyr}^{19}$} & 6.50 & 4.10 & $3.00,2.71$ & & & $2,6 \mathrm{H}, 7.14$ & 7 & ca. 11 \\
\hline & & & & & & $3,5 \mathrm{H}, 6.98$ & & \\
\hline $\operatorname{Pro}^{20}$ & & 4.90 & $2.28,2.90$ & & $3.70,3.62$ & & & \\
\hline Asp $^{21}$ & 7.92 & 2.38 & 2.68 & & & & & \\
\hline \multirow[t]{2}{*}{$\operatorname{Pro}^{22}$} & & 2.92 & $2.24,1.08$ & 1.90 & $3.22,3.18$ & & & \\
\hline & & & & 1.50 & & & & \\
\hline $\mathrm{Glu}^{23}$ & 8.39 & 4.42 & $2.18,2.03$ & 2.51 & & & ca. 8 & \\
\hline Gly $^{24}$ & 8.31 & 4.02 & & & & & 6 & \\
\hline Gly $^{25}$ & 8.40 & 4.00 & & & & & 6 & \\
\hline Gly $^{26}$ & 8.37 & 3.95 & & & & & & \\
\hline $\mathrm{NH}_{2}$ & & & & & & term NH, 7.53, 7.11 & & \\
\hline
\end{tabular}

cross-peaks for $d_{\alpha \mathrm{N}}$ and $d_{\alpha \delta}$ connectivities. The key to their assignment, summarized in Table 4 , is a cluster of nOe's in which the protons of $\mathrm{Asp}^{21}$ play a central role. Satisfying the data in Table 4 leads to cis-peptide bonds for $\mathrm{Pro}^{20}$, $\mathrm{Pro}^{22}$, and $\mathrm{Glu}^{23}$. The assignment of the alpha protons of $\mathrm{Asp}^{21}$ and Pro $^{22}$ was validated by the HMQC spectrum.

3.3. The Conformation of DX60. Forty-six distance constraints extracted from the ROESY spectrum and the NOE difference experiments were used in the modeling calculations (Table 5). This set consists of 12 intraresidue constraints, 30 sequential constraints, but only 4 mediumrange constraints and no long-range constraints. Half of these constraints involve the more flexible aromatic rings. The few violations of the constraints in the modeling calculations did not exceed $0.05 \AA$. Constraints on $\phi$ were obtained in the three cases- $\mathrm{Tyr}^{11}, \mathrm{Cys}^{17}$, and $\mathrm{Thr}^{18}$ - where the value of ${ }^{3} J_{\mathrm{NH}, \alpha \mathrm{H}}$ was large enough $(\geq 9 \mathrm{~Hz})$ to enable an unambiguous interpretation of a nearly s-trans-dihedral angle.

We began our modeling of DX600's conformation with an in vacuo approach that has worked well for drugs such as erythromycin: an exhaustive search of conformational space and a constrained minimization [20-22]. However, 
TABLe 4: Sequential connectivities involving $\mathrm{Tyr}^{19}$ through Glu ${ }^{23}$.

\begin{tabular}{|c|c|c|c|c|c|}
\hline $\mathrm{X}=$ nOe or rOe & $\operatorname{Pro}^{20} \alpha \mathrm{H}$ & $\mathrm{Asp}^{21} \mathrm{NH}$ & $\operatorname{Pro}^{22} \alpha \mathrm{H}$ & $\mathrm{Pro}^{22} \beta \mathrm{H}$ & $\mathrm{Glu}^{23} \beta \mathrm{H}$ \\
\hline $\operatorname{Tyr}^{19} \alpha \mathrm{H}$ & & $\mathrm{X}$ & & & \\
\hline Tyr $^{19} 2,6 \mathrm{H}$ & $\mathrm{X}$ & $\mathrm{X}$ & & & \\
\hline $\mathrm{Asp}^{21} \alpha \mathrm{H}$ & & & $\mathrm{X}$ & & \\
\hline $\mathrm{Asp}^{21} \beta \mathrm{H}$ & & & $\mathrm{X}$ & & \\
\hline $\operatorname{Pro}^{22} \alpha \mathrm{H}$ & & & & & $\mathrm{X}$ \\
\hline $\operatorname{Pro}^{22} \beta \mathrm{H}$ & & & & & $\mathrm{X}$ \\
\hline
\end{tabular}

TABLE 5: rOe distance constraints on the structure of DX600.

\begin{tabular}{|c|c|}
\hline Ac & Ac Me/Gly ${ }^{1} \mathrm{NH}, 4.0 \AA$ \\
\hline Gly $^{1}$ & $\mathrm{Gly}^{1} \alpha \mathrm{H} / \mathrm{Asp}^{2} \mathrm{NH}, 4.0 \AA$ \\
\hline $\mathrm{Asp}^{2}$ & $\begin{array}{l}\text { Asp }^{2} \alpha \mathrm{H} / \mathrm{Tyr}^{3} \mathrm{NH}, 3.0 \AA ; \mathrm{Asp}^{2} \beta \mathrm{H} / \mathrm{Tyr}^{3} \text { 2,6H, 7.4 } \\
\text { Asp }^{2} \alpha \mathrm{H} / \mathrm{Tyr}^{3} \text { 3,5H, } 6.4 \AA\end{array}$ \\
\hline \multirow[t]{2}{*}{$\mathrm{Tyr}^{3}$} & $\begin{array}{l}\mathrm{Tyr}^{3} \alpha \mathrm{H} / \mathrm{Tyr}^{3} 3,5 \mathrm{H}, 6.4 \AA ; \mathrm{Tyr}^{3} \beta \mathrm{H} / \mathrm{Tyr}^{3} 3,5 \mathrm{H}, 7.4 \AA ; \mathrm{Tyr}^{3} \\
\text { NH/Ser }{ }^{4} \mathrm{NH}, 4 \AA\end{array}$ \\
\hline & $\operatorname{Tyr}^{3} \alpha \mathrm{H} / \operatorname{Ser}^{4} \mathrm{NH}, 4 \AA$ \\
\hline $\mathrm{Ser}^{4}$ & $\operatorname{Ser}^{4} \mathrm{NH} / \mathrm{His}^{5} \mathrm{NH} 4 \AA$; $\operatorname{Ser}^{4} \beta \mathrm{H} / \mathrm{His}^{5} \mathrm{NH}, 5 \AA$ \\
\hline $\mathrm{His}^{5}$ & $\begin{array}{l}\operatorname{His}^{5} \alpha \mathrm{H} / \mathrm{His}^{5} 4 \mathrm{H}, 4 \AA ; \mathrm{His}^{5} \beta \mathrm{H}(\text { both }) / \mathrm{His}^{5} 4 \mathrm{H}, 4 \AA \\
\text { His }^{5} \beta \mathrm{H} / \mathrm{Cys}^{6} \beta \mathrm{H}, 5 \AA\end{array}$ \\
\hline Cys $^{6}$ & $\mathrm{Cys}^{6} \mathrm{NH} / \mathrm{Ser}^{7} \mathrm{NH}, 4 \AA ; \mathrm{Cys}^{6} \alpha \mathrm{H} / \operatorname{Ser}^{7} \beta \mathrm{H}, 5 \AA$ \\
\hline $\mathrm{Pro}^{8}$ & $\operatorname{Pro}^{8} \alpha \mathrm{H} / \mathrm{Leu}^{9} \mathrm{NH}, 3 \AA$ \\
\hline $\mathrm{Leu}^{9}$ & Leu $^{9} \delta \mathrm{H}($ both $) / \mathrm{Tyr}^{11} 3,5 \mathrm{H}, 7.4 \AA$ \\
\hline $\operatorname{Arg}^{10}$ & $\operatorname{Arg}^{10} \alpha \mathrm{H} / \operatorname{Tyr}^{11} \mathrm{NH}, 3 \AA ; \operatorname{Arg}^{10} \beta \mathrm{H} / \operatorname{Tyr}^{11} 2,6 \mathrm{H}, 7.4 \AA$ \\
\hline $\operatorname{Tyr}^{11}$ & $\begin{array}{l}\operatorname{Tyr}^{11} \alpha \mathrm{H} / \mathrm{Tyr}^{12} \mathrm{NH}, 3 \AA ; \operatorname{Tyr}^{11} \beta \mathrm{H}(\text { both }) / \operatorname{Tyr}^{12} 2,6 \mathrm{H} \text {, } \\
\mathbf{6 . 4} \AA\end{array}$ \\
\hline $\operatorname{Tyr}^{12}$ & $\operatorname{Tyr}^{12} \beta \mathrm{H}($ both $) / \operatorname{Tyr}^{12} 2,6 \mathrm{H} 5.4 \AA$ \\
\hline $\operatorname{Tr} p^{14}$ & $\begin{array}{l}\operatorname{Trp}^{14} \alpha \mathrm{H} / \operatorname{Trp}^{14} 4 \mathrm{H} 4 \AA ; \operatorname{Tr}^{14} \beta \mathrm{H} / \operatorname{Tr}^{14} 4 \mathrm{H}, 5 \AA ; \\
\operatorname{Trp}^{14} \beta \mathrm{H} / \operatorname{Trp}^{15} 2 \mathrm{H}, \mathbf{5} \AA\end{array}$ \\
\hline $\operatorname{Trp}^{15}$ & $\begin{array}{l}\operatorname{Trp}{ }^{15} \alpha \mathrm{H} / \operatorname{Trp}^{15} 4 \mathrm{H}, 4 \AA ; \operatorname{Trp}^{15} \beta \mathrm{H} / \operatorname{Tr}^{15} 4 \mathrm{H} 4 \AA \\
\operatorname{Trp}^{15} \alpha \mathrm{H} / \mathrm{Lys}^{16} \mathrm{NH}, 3 \AA\end{array}$ \\
\hline Lys $^{16}$ & Lys $^{16} \alpha \mathrm{H} /$ Cys $^{17} \mathrm{NH}, 3 \AA$ \\
\hline Cys $^{17}$ & $\mathrm{Cys}^{17} \alpha \mathrm{H} / \mathrm{Thhr}^{18} \mathrm{NH}, 4 \AA$ \\
\hline $\operatorname{Thr}^{18}$ & $\mathrm{Thr}^{18} \mathrm{NH} / \mathrm{Tyr}^{19} \mathrm{NH}, 4 \AA$ \\
\hline \multirow[t]{2}{*}{$\operatorname{Tyr}^{19}$} & $\operatorname{Tyr}^{19} \beta \mathrm{H} / \operatorname{Tyr}^{19}$ 2,6H, 7.4 $\AA ; \operatorname{Tyr}^{19}$ 2,6H/Pro ${ }^{20} \alpha \mathrm{H} 6.4 \AA$ \\
\hline & Tyr $^{19} \alpha \mathrm{H} /$ Asp $^{21} \mathrm{NH}, \mathbf{6 . 4} \AA ;$ Tyr $^{19}$ 2,6H/Asp ${ }^{21} \mathrm{NH} 6.4 \AA$ \\
\hline Asp $^{21}$ & $\operatorname{Asp}^{21} \alpha \mathrm{H} / \operatorname{Pro}^{22} \alpha \mathrm{H}, 4 \AA ; \operatorname{Asp}^{21} \alpha \mathrm{H} / \operatorname{Pro}^{22} \beta \mathrm{H}, 4 \AA$ \\
\hline Pro $^{22}$ & $\operatorname{Pro}^{22} \alpha \mathrm{H} / \mathrm{Glu}^{23} \beta \mathrm{H}, 5 \AA ; \operatorname{Pro}^{22} \beta \mathrm{H} / \mathrm{Glu}^{23} \beta \mathrm{H}, 6 \AA$ \\
\hline $\mathrm{Glu}^{23}$ & $\mathrm{Glu}^{23} \alpha \mathrm{H} / \mathrm{Gly}^{24} \mathrm{NH}, 3 \AA$ \\
\hline Gly $^{24}$ & $\mathrm{Gly}^{24} \alpha \mathrm{H} / \mathrm{Gly}^{25} \mathrm{NH}, 4 \AA$ \\
\hline
\end{tabular}

If the constraint is in bold, a pseudoatom correction [13] is applied.

this method yielded a result that disagreed with the NMR evidence. The set of low energy conformers generated by in vacuo modeling yielded a well-defined, nearly spherical structure. The magnitude of the monopole-monopole interactions between the six charged side chains argues that the role of the solvent and its large dielectric constant must be explicitly included in the modeling calculations. Therefore, in a second series of calculations, one molecule of DX600 was imbedded in a rectangular box of water molecules. A series of MD simulations for aquated DX600 yielded a predominantly

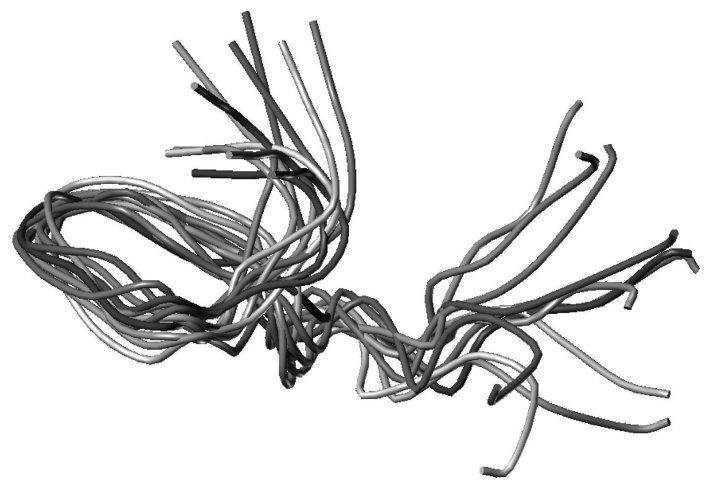

FIGURE 4: Overlay of the structures of DX600 generated by the final 11 cycles of the MD annealing process. The tubes trace the peptide backbone.

random coil conformation for DX600 in water. Figure 4 shows the overlay of the 11 energy-minimized structures obtained in the final MD cycles. The average RMSD using all backbone atoms is $3.5 \AA$ and using the backbone atoms on residues $\mathrm{Ser}^{4}$ through $\mathrm{Glu}^{23}$ is $2.6 \AA$. Overall, the backbone of DX600 forms an overhand knot with frayed ends. The poor overlay of the structures at the ends shows that the peptide does not have a well-defined conformation at the amino and carboxy termini. Except for the turn required by the disulfide bond between the two cysteines, the peptide adopts an extended, nonspherical conformation which explains the small translational diffusion constant and the short value of $T_{2}$. Given the size of the peptide and its extended conformation, most residues are exposed to the solvent. This exposure explains the relative flexibility of the leucine, threonine, glutamate, and aromatic side chains. The six charged side chains extend into the solvent so that peptide-water Coulombic interactions make a significant contribution to DX600's conformation.

\section{Conclusions}

Although DX600 has a predominantly random-coil structure, the constraint of the disulfide bond yields the formation of a loop. Several lessons were learned from this study. A complete assignment of the proton spectrum of the most abundant conformer was only achieved by combining many sources of information. The modeling of a small peptide with a large fraction of charged residues must be handled with care. The development of a structural model from 
the NMR data required explicit solvation. In vacuo modeling calculations led to an incorrect result.

\section{Acknowledgment}

Financial support for this project was provided by the Frederic J. Robbins Fund for Chemistry at Pomona College.

\section{References}

[1] A. A. Patchett and E. H. Cordes, "The design and properties of $\mathrm{N}$-carboxyalkyldipeptide inhibitors of angiotensin-converting enzyme," Advances in Enzymology and Related Areas of Molecular Biology, vol. 57, pp. 1-84, 1985.

[2] J. L. Stanton and R. L. Webb, "Endogenous vasoactive peptides," in Burger's Medicinal Chemistry \& Drug Discovery, D. J. Abraham, Ed., vol. 3, chapter 4, John Wiley \& Sons, New York, NY, USA, 6th edition, 2003.

[3] Physicians' Desk Reference, Thomson Healthcare, Montvale, NJ, USA, 62nd edition, 2008.

[4] R. Natesh, S. L. U. Schwager, H. R. Evans, E. D. Sturrock, and K. R. Acharya, "Structural details on the binding of antihypertensive drugs captopril and enalaprilat to human testicular angiotensin I-converting enzyme," Biochemistry, vol. 43, no. 27, pp. 8718-8724, 2004.

[5] A. G. Tzakos, N. Naqvi, K. Comporozos et al., "The molecular basis for the selection of captopril cis and trans conformations by angiotensin I converting enzyme," Bioorganic and Medicinal Chemistry Letters, vol. 16, no. 19, pp. 5084-5087, 2006.

[6] Y. Sakamoto, T. Ishii, I. Oonishi, and T. Ohmoto, "Conformational analysis of Ramipril (HOE 498) in a solution by NMR," Journal of Molecular Structure, vol. 245, no. 3-4, pp. 379-389, 1991.

[7] S. R. Tipnis, N. M. Hooper, R. Hyde, E. Karran, G. Christie, and A. J. Turner, "A human homolog of angiotensinconverting enzyme: cloning and functional expression as a captopril-insensitive carboxypeptidase," The Journal of Biological Chemistry, vol. 275, no. 43, pp. 33238-33243, 2000.

[8] P. Towler, B. Staker, S. G. Prasad et al., "ACE2 X-Ray structures reveal a large hinge-bending motion important for inhibitor binding and catalysis," The Journal of Biological Chemistry, vol. 279, no. 17, pp. 17996-18007, 2004.

[9] M. A. Crackower, R. Sarao, G. Y. Oudit et al., "Angiotensinconverting enzyme 2 is an essential regulator of heart function," Nature, vol. 417, no. 6891, pp. 822-828, 2002.

[10] J. A. Hernández Prada, A. J. Ferreira, M. J. Katovich et al., "Structure-based identification of small-molecule angiotensin-converting enzyme 2 activators as novel hypertensive agents," Hypertension, vol. 51, no. 5, pp. 1312-1317, 2008.

[11] T. J. Parry, L. Sekut, C. A. Rosen et al., "Methods and compositions for modulating ACE-2 activity," U.S. Patent 6,9009,033, May 2005.

[12] L. Huang, D. J. Sexton, K. Skogerson et al., "Novel peptide inhibitors of angiotensin-converting enzyme 2," The Journal of Biological Chemistry, vol. 278, no. 18, pp. 15532-15540, 2003.

[13] K. Wüthrich, NMR of Proteins and Nucleic Acids, John Wiley \& Sons, New York, NY, USA, 1986.

[14] R. K. Harris, E. D. Becker, S. M. Cabral De Menezes, R. Goodfellow, and P. Granger, "NMR nomenclature. Nuclear spin properties and conventions for chemical shifts," Pure and Applied Chemistry, vol. 73, no. 11, pp. 1795-1818, 2001.
[15] S. Berger and W. Braun, 200 and More NMR Experiments, Wiley-VCH, Weinheim, Germany, 1998.

[16] T. L. Hwang and A. J. Shaka, "Cross relaxation without TOCSY: transverse rotating-frame overhauser effect spectroscopy," Journal of the American Chemical Society, vol. 114, no. 8, pp. 3157-3159, 1992.

[17] S. L. Gordon and K. Wüterich, "Transient proton-proton overhauser effects in horse ferrocytochrome," Journal of the American Chemical Society, vol. 100, no. 22, pp. 7094-7096, 1978.

[18] D. H. Wu, A. D. Chen, and C. S. Johnson, "An improved diffusion-ordered spectroscopy experiment incorporating bipolar-gradient pulses," Journal of Magnetic Resonance, Series A, vol. 115, no. 2, pp. 260-264, 1995.

[19] L. G. Longsworth, "The mutual diffusion of light and heavy water," Journal of Physical Chemistry, vol. 64, no. 12, pp. 19141917, 1961.

[20] W. E. Steinmetz, J. D. Sadowsky, J. S. Rice, J. J. Roberts, and Y. K. Bui, "Determination of the aqueous-phase structure of 6-O-methylerythromycin from NMR constraints," Magnetic Resonance in Chemistry, vol. 39, no. 4, pp. 163-172, 2001.

[21] W. E. Steinmetz, B. L. Shapiro, and J. J. Roberts, "The structure of erythromycin enol ether as a model for its activity as a motilide," Journal of Medicinal Chemistry, vol. 45, no. 22, pp. 4899-4902, 2002.

[22] W. E. Steinmetz, A. Sparrow, and M. Somsouk, "Determination of the three-dimensional, solution-phase structure of the macrolide antibiotic oxolide in $\mathrm{CDCl}$ and $\mathrm{D}_{2} \mathrm{O}$ from NMR constraints," Magnetic Resonance in Chemistry, vol. 43, no. 1, pp. 16-20, 2005.

[23] T. A. Halgren, "MMFF VII. Characterization of MMFF94, MMFF94s, and other widely available force fields for conformational energies and for intermolecular-interaction energies and geometries," Journal of Computational Chemistry, vol. 20, no. 7, pp. 730-748, 1999.

[24] N. J. Baxter and M. P. Williamson, "Temperature dependence of ${ }^{1} \mathrm{H}$ chemical shifts in proteins," Journal of Biomolecular NMR, vol. 9, no. 4, pp. 359-369, 1997.

[25] W. E. Steinmetz, T. I. Bianco, M. Zollinger, and D. Pesiri, "Characterization of the multiple forms of mast cell degranulating peptide by NMR spectroscopy," Peptide Research, vol. 7, no. 2, pp. 77-82, 1994.

[26] A. Carrington and A. G. McLachlan, Introduction to Magnetic Resonance, Harper, New York, NY, USA, 1967. 


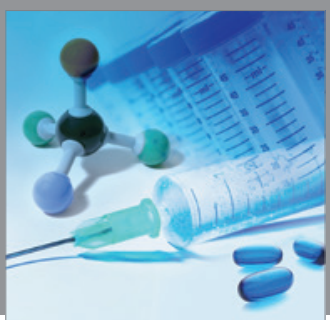

International Journal of

Medicinal Chemistry

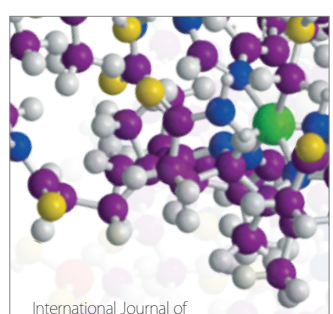

Carbohydrate Chemistry

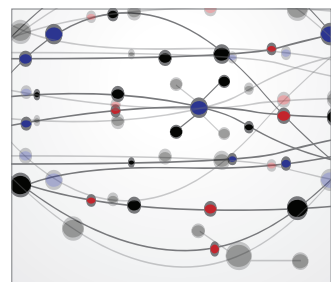

The Scientific World Journal
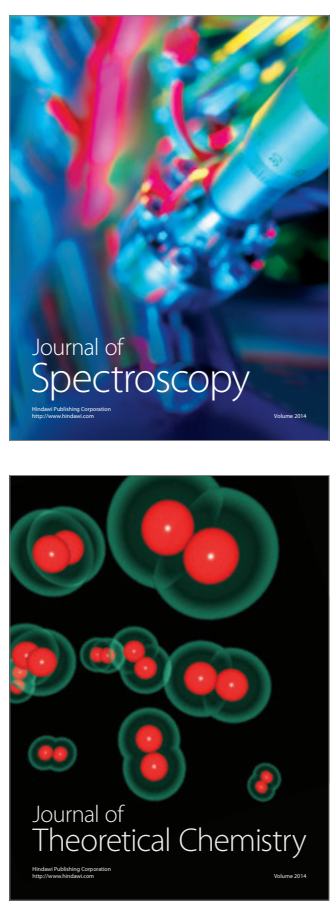
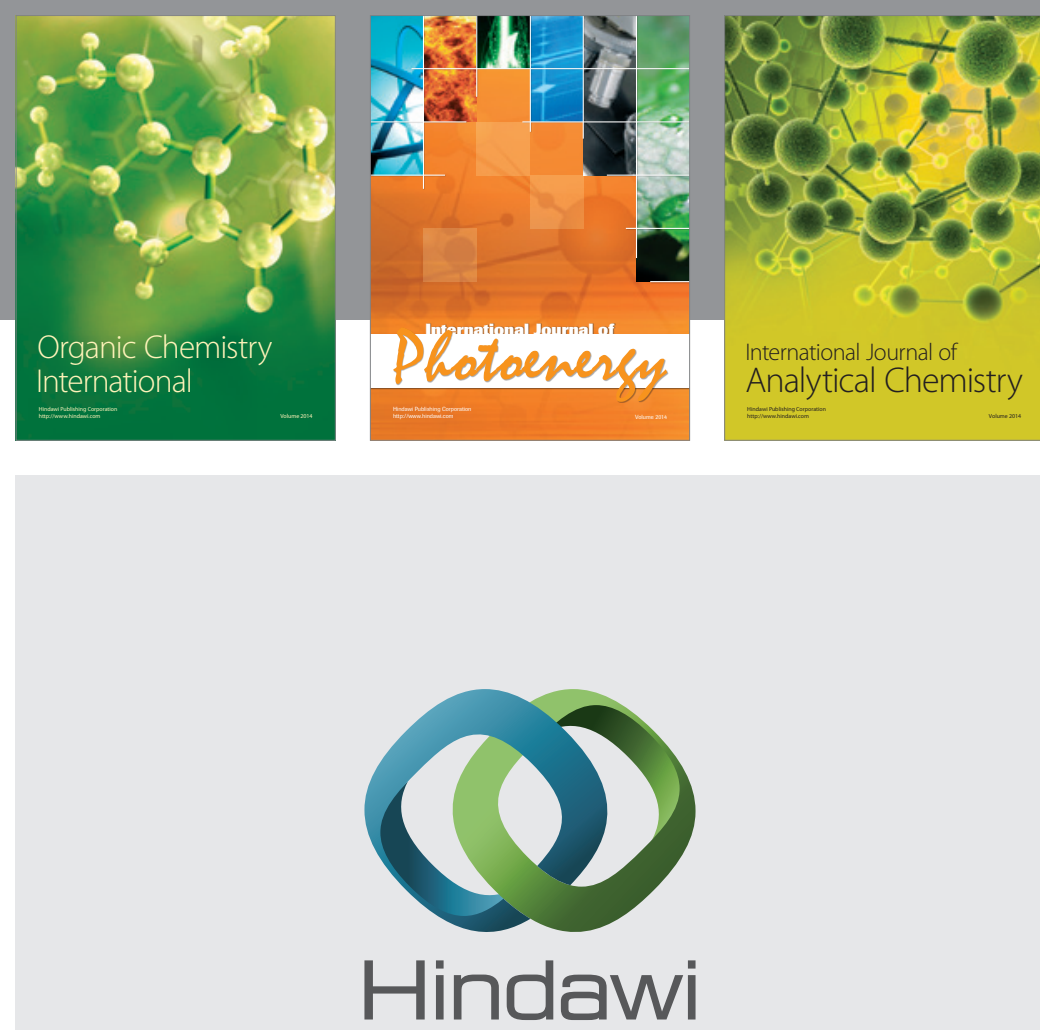

Submit your manuscripts at

http://www.hindawi.com
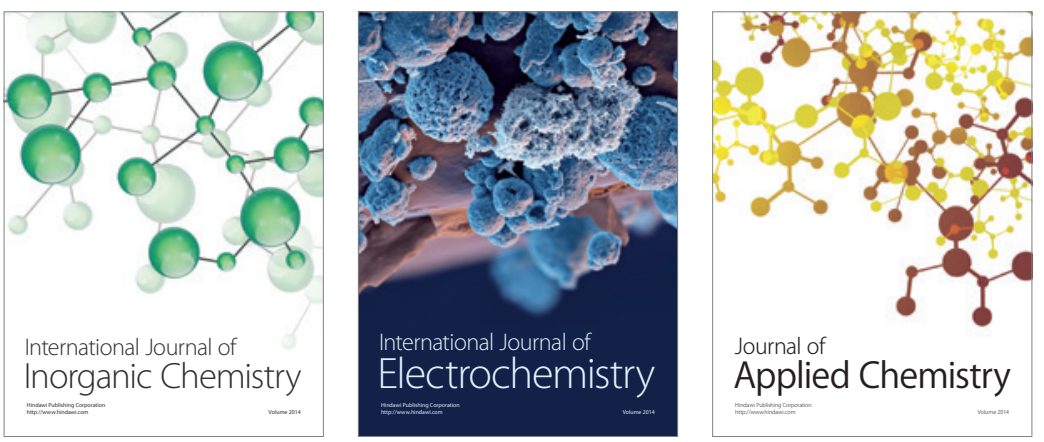

Journal of

Applied Chemistry
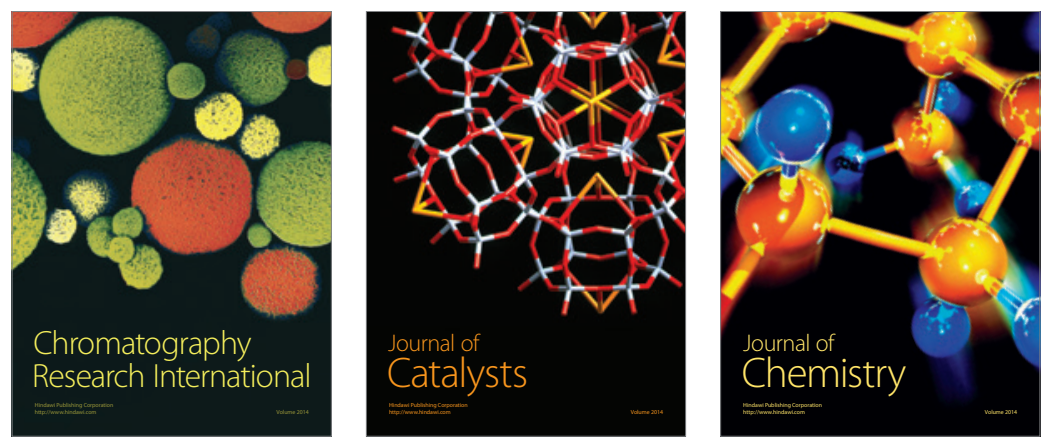
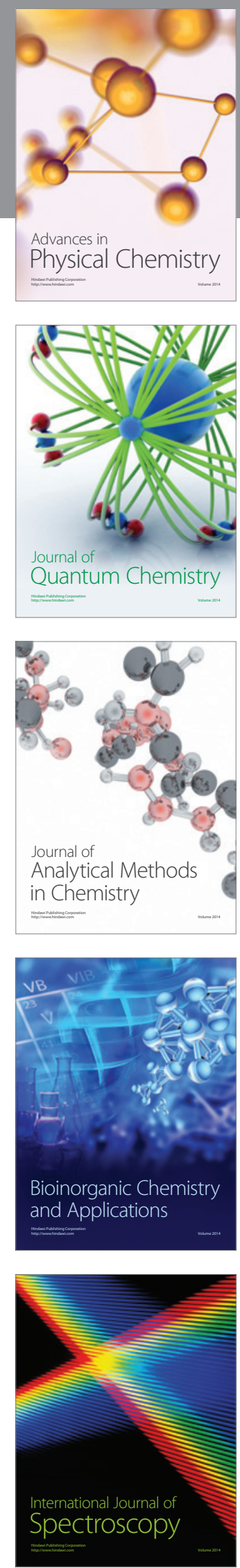